\title{
Preparing Locally Encoded Electronic Finding Aid Inventories for Union Environments: A Publishing Model for Encoded Archival Description

This paper will briefly discuss encoded archival description (EAD) finding aids, the workflow and process involved in encoding finding aids using EAD metadata standard, our institution's current publishing model for $E A D$ finding aids, current EAD metadata enhancement, and new developments in our publishing model for EAD finding aids at Florida State University Libraries. For brevity and within the scope of this paper, FSU Libraries will be referred to as FSU, electronic EAD finding and/ or archival finding aid will be referred as EAD or EADs, and locally encoded electronic EAD finding aids inventories will be referred to as EADs @ FSU.

\section{What is an EAD finding aid?}

Many scholars, researchers, and learning and scholarly communities are unaware of the existence of rare, historic, and scholarly primary source materials such as inventories, registers, indexes, archival documents, papers, and manuscripts located within institutions' collections/holdings, particularly special collections and archives. A finding aid-a document providing information on the scope, contents, and locations of collections/ holdings-serves as both an information provider and guide for scholars, researchers, and learning and scholarly communities, directing them to the exact locations of rare, historic, and scholarly primary source materials within institutions' collections/holdings, particularly noncirculating and rare materials. The development of the finding aid led to the institution of an encoding and markup language that was software/hardware independent, flexible, extensible, and allowed online presentation on the World Wide Web.

In order to provide logical structure, content presentation, and hierarchical navigation, as well as to facilitate Internet access of finding aids, the University of California-Berkeley Library in 1993 initiated a cooperative project that would later give rise to development of the nonproprietary SGML-based, XML-compliant, machine-readable markup language encoding finding aid standard, encoded archival description (EAD) document type definition (DTD) (LOC, 2006a). Thus, an EAD finding aid is a finding aid that has been encoded using Encoded Archival Description and which should be validated against an EAD DTD. The EAD XML that produces the EAD finding aid via an extensible style sheet

Plato L. Smith II (psmithii @fsu.edu) is Digital Initiatives Librarian at Florida State University Libraries, Tallahassee. language (XSL) should be checked for well-formed-ness via an XML validator (i.e. XML Spy, Oxygen, etc.) to ensure proper nesting of EAD metadata elements

"The EAD Document Type Definition (DTD) is a standard for encoding archival finding aids using Extensible Markup Language (XML)" (LOC, 2006c). An EAD finding aid includes descriptive and generic elements along with attribute tags to provide descriptive information about the finding aid itself, such as title, compiler, compilation date, and the archival material such as collection, record group, series, or container list.

Florida State University Libraries has been creating locally encoded electronic encoded archival description (EAD) finding aids using a Note Tab Light text editor template and locally developed XSL style sheets to generate multiple EAD manifestations in HTML, PDF, and XML formats online for over two years. The formal EAD encoding descriptions and guidelines are developed with strict adherence to the Best Practice Guidelines for the Implementation of EAD Version 2002 in Florida Institutions (FCLA, 2006), Manuscript Processing Reference Manual (Altman \& Nemmers, 2006), and EAD Version 2002. An EAD Note Tab Light template is used to encode findings down to the collection level and create EAD XML files. The EAD XML files are tranformed through XSL stylesheets to create EAD finding aids for select special collections.

\section{EAD workflow, processes, and publishing model}

The certified archivist and staff in Special Collections and a graduate assistant in the Digital Library Center encode finding aids in EAD metadata standard using an EAD clip and EAD template library in Note Tab Light text editor via data entry input for the various descriptive, administrative, generic elements, and attribute metadata element tags to generate EAD XML files. The EAD XML files are then checked for validity and well-formed-ness using XML Spy 2006. Currently, EAD finding aids are encoded down to the folder level, but recent Florida Heritage Project 2005-2006 grant funding has allowed selected special collections finding aids to be encoded down to the item level.

Currently, we use two XSL style sheets, ead2html.xsl and ead2pdf.xsl, to generate HTML and PDF formats, and simply display the raw XML as part of rendering EAD finding aids as HTML, PDF, and XML and presenting these manifestations to researchers and end users. The ead2html.xsl style sheet used to generate the HTML versions was developed with specifications such as use of FSU seal, color, and display with input from the Special Collections department head. The ead2pdf.xsl style sheet used to generate PDF versions uses XSL-FO (formatting 
object), and was also developed with specifications for layout and design input from the Special Collections department head. The HTML versions are generated using XML Spy Home Edition with built-in XSLT, and the PDF versions are generated using Apache Formatting Object Processor (FOP) software from the command line. EAD finding aids, EADs @ FSU, are available in HTML, PDF, and XML formats (see figure 1). The style sheets used, EAD authoring software, and EADs @ FSU original site are available via www.lib.fsu.edu/dlmc/dlc/ findingaids.

\section{Enriching EAD metadata}

As EAD standards and developments in the archival community advance, we had to begin a way of enriching our EAD metadata to prepare our locally encoded EAD finding aids for future union catalog searching and OPAC access. The first step toward enriching the metadata of our EAD finding aids was to use RLG EAD Report Card (OCLC, 2008) on one of our EAD finding aids. The test resulted in the display of missing Required (Req), Mandatory (M), Mandatory if applicable (MA), Recommended (Rec), Optional (Opt), and Encoding Analogs (relatedencoding and encodinganalog attributes) metadata elements (see figure 2).

The second test involved reference Online Archive of California Best Practices Guidelines (OAC BPG), specifically Appendix B (CDL, 2005, I 2), to create a Formal Public Identifier (FPI) for our EAD finding aids and make the EAD FPIs Describing Archives Content Standards (DACS)-compliant. This second test resulted in the creation of our very first DACScompliant EAD Formal Public Identifier.

\section{Example: \\ $<$ eadid countrycode= "US" \\ identifier= "MSS2003004" \\ mainagencycode="FTaSU" publicid="-//Florida \\ State University::Strozier Library::Special \\ Collections//TEXT (US::FTaSU::FTaSU2003004:: \\ Bernard F. Sliger Collection)//EN">FTaSU2003004. \\ $x m l</ e a d i d>$}

The RLG EAD Report Card and Appendix $B$ of OAC BPG together helped us modify our EAD finding aid encoding template and workflow to enrich the EAD document identifier $<$ did $>$ metadata tag element, include missing mandatory EAD metadata elements, and develop FPIs for all of our EAD finding aids.
Prior to recent new developments in the publishing model of EAD finding aids at FSU Libraries, the EAD finding aids in our EADs @ FSU inventories could not be easily found using traditional Web search engines, were part of the so-called "deep Web," (Prom \& Habing, 2002) and were "unidimensional in that they [were] based upon the assumption that there [was] an object in a library and there [was] a descriptive surrogate for that object, the cataloging record" (Hensen, 1999). EAD finding aids in our EADs @ FSU inventories did not have a descriptive surrogate catalog record and lacked the relevant related encoding and analog metadata elements within the EAD metadata with which to facilitate "metadata crosswalks" - mapping one metadata standard with another metadata standard to facilitate crosssearching. "To make the metadata in EAD instance as robust as possible, and to allow for crosswalks to other encoding schemes, we mandate the inclusion of the relatedencoding and encodinganalog attributes in both the $<$ eadheader > and <archdesc > segments" (Meissner, et al., 2002). Incorporating an EAD quality checking tool such as RLG BPG and EAD compliance such as DACS when

\section{Special Collections Inventories \\ Bernard F. Sliger Collection \\ ID:FTaSU2003004 \\ HTMLI POF I XML (Right-click to download as XML file)}

Blue Ridge Institute for Southern Community Service Executives Collection ID:FTaSU1976019

HTMLI PDF | XML (Right-click to download as XML file)

Cinema Corporation of America Collection ID:FTaSU2004008

HTMLI PDF | XML (Right-click to download as XML file)

Figure 1. EAD finding aids in HTML, PDF, and XML format

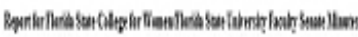

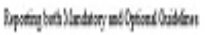

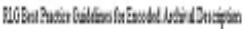

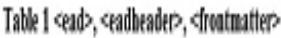

\begin{tabular}{|c|c|c|c|c|}
\hline thentaria & $\begin{array}{c}\text { Sminkedill } \\
\text { thatil }\end{array}$ & sens & IWlatuken & Muthryars \\
\hline aliabing & zenewhr & 4 & $\begin{array}{l}\text { Ywey fluperions } \\
\text { Infons }\end{array}$ & ins \\
\hline aliabudr & denterstry & y & 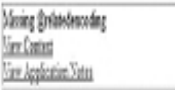 & 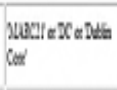 \\
\hline ditutult & 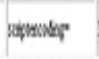 & sit & 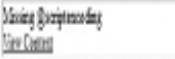 & $w \mid w$ \\
\hline
\end{tabular}

Figure 2. RLG EAD Report Card of XML EAD file 
authoring EADs, will assist in improving EAD encoding and EAD finding aids publishing model.

\section{Some key issues with creating and managing EAD finding aids}

One of the major issues with creating and managing EAD finding aids is the set of rules used for describing papers, manuscripts, and archival documents. The former set of rules used for providing consistent descriptions and Anglo-American Cataloging Rules (AACR) bibliographic catalog compliance for papers, manuscripts, and archival documents down to collection level was Archives, Personal Papers, and Manuscripts (APPM), which was complied by Steven L. Hensen and published by the Library of Congress in 1983. However, the need for more description granularity down to the item level, enhanced bibliographic catalog specificity, MARC and EAD metadata standards implementations and metadata standards crosswalks, and inclusion of descriptors of archival material types beyond personal papers and manuscripts prompted the development of Describing Archives: A Content Standard (DACS), published in 2004 with the second edition published in 2007. "DACS [U.S. implementation of international standard for the description of archival materials and their creators] is an output-neutral set of rules for describing archives, personal papers, and manuscripts collections, and can be applied to all material types "(Pearce-Moses, 2005). Some international standards for describing archival materials are General International Standard Archival Description $\operatorname{ISAD}(G)$

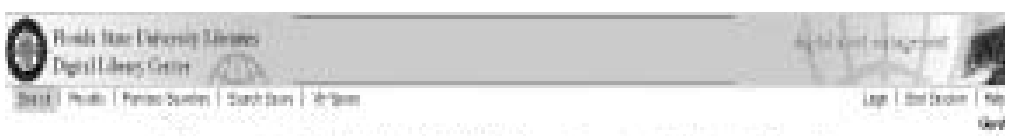

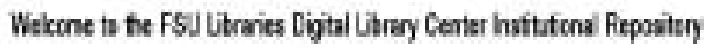

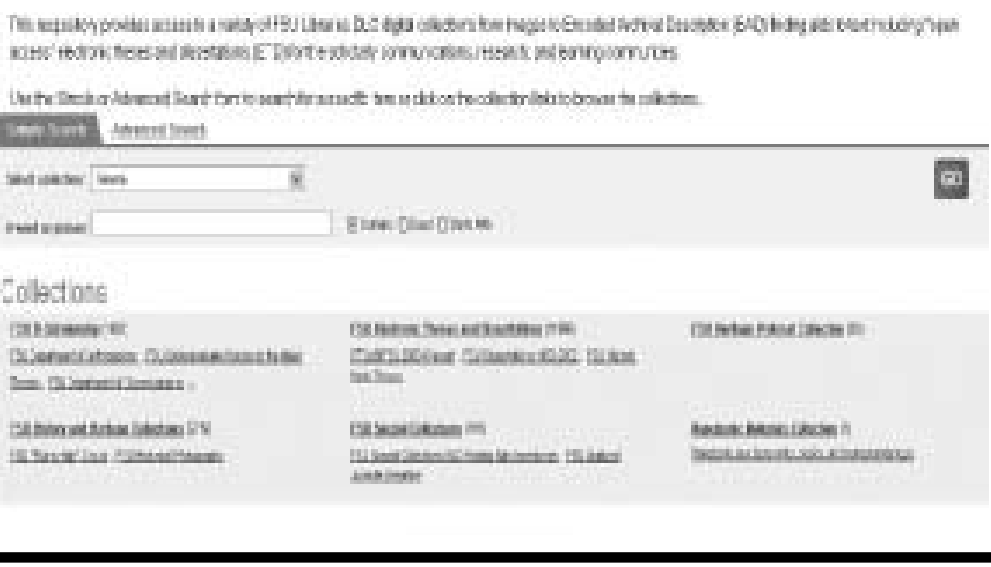

Figure 3. Online search GUI for EAD finding aids and digital collections within IR and International Standard Archival Authority Record for Corporate Bodies, Persons, and Families [ISAAR(CPF)].

Other issues with creating and managing EAD finding aids include (list not exhaustive):

1. Online presentation of finding aids

2. Exposing finding aids electronically for searching

3. Provision of a search interface to search finding aids

4. Online public access catalog record (MARC) and link to finding aids

5. Finding aids linked to digitized content of collections

EADs@ $@$ FSU exist in HTML for online presentation, PDF for printing, and XML for exporting, which allow researchers greater flexibility and options in the information-gathering and research processes and have improved the way archivists communicated guides to archival collections with researchers as opposed to paper finding aids physically housed within institutions. EADs @ FSU have existed online in HTML, PDF, and XML formats for two years in a static HTML document and then moved to Drupal (MySQL database with PHP) for about one year, which improved online maintenance but not researcher functionality. However, the purchase and upgrade of a digital content management system marked a huge advancement in the development of our EAD finding aids implementation and thus resolutions to issues numbers $1-3$.

Researchers now have a single-point search interface to search EADs @ FSU across all our digital collections / institutional repository (see figure 3); the ability to search within the finding aids via full-text indexing of PDFs; the option of brief (thumbnails with EAD, HTM, PDF, and XML manifestation icons), table (title, creator, and identifier), and full (complete EAD finding aid DC record with manifestations) views of search results, which provides different levels of exposures of EAD finding aids; and the ability to save/e-mail search results.

Future initiatives are underway to enhance EADs@ FSU implementation via the creation of EAD MARC records through Dublin Core to MARC metadata crosswalk, to deep link to EAD finding aids via 856 field in MARC records, and to begin digitizing and linking to EAD finding aids archival content via digital archival object $<$ dao $>$ EAD element. $<$ dao $>$ is "linking element that uses the attributes ENTITYREF or HREF to connect the finding aid information to electronic representations of the described materials. The <dao $>$ and $<$ daogrp $>$ elements allow the content of an archival collection or record 
group to be incorporated in the finding aid" (LOC, 2006b). We have opted to create basic Dublin Core records of EAD finding aids based on the information in the EAD finding aids descriptive summary (front matter) first and then crosswalk to MARC, but are cognizant that this current workflow is subject to change in the pursuit of advancement.
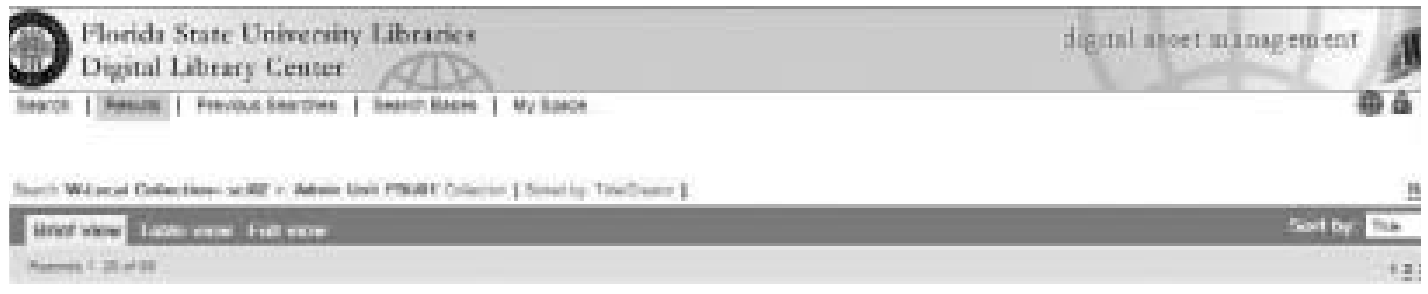

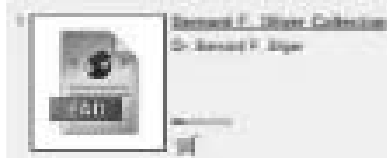

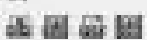

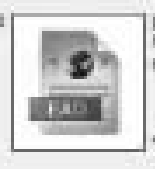

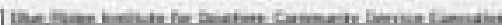
cente

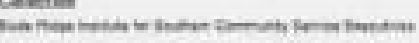

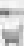
可田数

Figure 4. EAD finding aids in EAD (default), HTML, PDF, and XML manifestations

However, we are seeking ways to improve the EAD workflow and EAD MARC record creation through more communication and future collaboration with the FSU Libraries cataloging department.

\section{Number of finding aids and percent of EADs @ FSU}

As of February 16, 2006, we had 700 collections with finding aids in which 220 finding aids are electronic and encoded in HTML (31 percent of total finding aids). From the 220 electronic finding aids, 60 are available as HTML, PDF, and XML finding aids (20 percent of electronic finding aids are EADs @ FSU). However, we currently have 63 EAD finding aids available online in HTML, PDF, and XML formats.

\section{New developments in publishing EADs @ FSU}

Current EADs@ FSU include the recommendations from test 1 and test 2 (RLG BPG and DACS compliance) which were discussed earlier and the digital content management system (i.e. DigiTool) creates a descriptive digital surrogate of the EAD objects in the form of brief and basic Dublin Core metadata records for each EAD finding aid along with multiple EAD manifestations (see figure 4).

We have successfully built and launched our first new digital collection, FSU Special Collections EAD Inventories, in DigiTool 3.0 as part of FSU Libraries DLC Digital Repository (http://digitool3.lib.fsu.edu/R/), a relational database digital content management system (DCMS). DigiTool has an Oracle 9i relational database management system backend, searchable Web-based GUI, a default EAD style sheet that allows full-text searching of EADs, supports MARC, DC, METS metadata standards, JPEG2000 (built in tools for images and thumbnails) as well as Z39.50 and OAI protocols which will enable resource discovery and exposing of EADs @ FSU.

You can visit FSU Special Collections EAD Finding Aids Inventories at http://digitool3.lib.fsu.edu/R/? func $=$ collections-result\&collection_id=1076.

\section{National, international, and regional aggregation of finding aids initiatives}

RLG's ArchiveGrid (http://archivegrid.org/web/index. jsp) is an international, cross-institutional search constituting the aggregation of primary source archival materials of more than 2,500 research libraries, museums, and archives with a single-point interface to search archival collections from across research institutions. Other international, cross-institutional searches of aggregated archival collections are:

- Intute: arts\& humanities in the United Kingdom www.intute.ac.uk/artsandhumanities/ cgi-bin/browse.pl?id=200025 (international guide to subcategories of archival materials)

- Archives Made Easy www.archivesmade easy.org (guide to archives by country)

There are also some regional initiatives, which provide cross-institutional search of aggregations of finding aids:

- Publication of Archival Library and Museum Materials (PALMM) http:/ / palmm.fcla.edu (cross- 
institutional searches in FL - FSU participates, FL)

- Virginia Heritage: Guides to Manuscript and Archival Collections in Virginia http://ead.lib .virginia.edu/vivaead/ (cross-institutionalsearches in Virginia)

- Texas Archival Resources Online www.lib.utexas. edu/taro/ (cross-institutional searches in Texas)

- Online Archive of New Mexico http://elibrary .unm.edu/oanm/ (cross-institutional searches in New Mexico)

Awareness of regional, national, and international aggregation of finding aids initiatives and engagement in regional aggregation of finding aids will enable a consistent advancement in the development and implementation of EADs @ FSU.

\section{Acknowledgments}

FSU Libraries Digital Library Center and Special Collections Department, Florida Heritage Project funding (FCLA), Chuck F. Thomas (FCLA), and Robert McDonald (SDSC) assisted in the development, implementation, and success of EADs at FSU.

\section{References}

Altman, B. \& Nemmers, J. (2006). Manuscripts processing reference manual. Florida State University Special Collections.

California Digital Library (CDL). (2005). OAC best practice guidelines for encoded archival description, appendix $b$. formal public identifiers for finding aids. Retrieved October 6, 2006 from www.cdlib.org/inside/diglib/guidelines/bpgead/ bpgead_app.html\#d0e2995.

Digital Library Center, Florida State University Libraries. (2006). FSU special collections EAD finding aids inventories. Retrieved January 5, 2007 from http://digitool3.lib.fsu.edu/ $\mathrm{R} /$ ?func $=$ collections-result\&collection_id=1076.

Florida Center of Library Automation (FCLA). (2004). PALMM: publication of archival library and museum materials, archival collections. Retrieved January 7, 2007 from http://palmm.fcla .edu.

Florida Center for Library Automation (FCLA). (2006). Best practice guidelines for the implementaton of EAD version 2002 in Florida institutions. (John Nemmers, Ed.). Accessed April 21, 2008, at www.fcla.edu/dlini/OpeningArchives/new/ FloridaEADguidelines.pdf

Fox, M. (2003). The EAD cookbook - 2002 edition.Chicago: The Society of American Archivists. Retrieved October 6, 2006 from www.archivists.org/saagroups/ead/ead2002cookbook .html.

Hensen, S. L. (1999). NISTF II and EAD: The evolution of archival description. Encoded Archival Description: Context, Theory, and Case Studies (pp. 23-34). Chicago: The Society of American Archivsits

Library of Congress (LOC). (2006a). Development of the encoded archival description DTD. Retrieved October 6, 2006 from www.loc.gov/ead/eaddev.html.

Library of Congress (LOC). (2006b). Digital archival objectencoded archival description tag library-version 2002. Retrieved January 8, 2007 from www.loc.gov/ead/tglib.

Library of Congress (LOC). (2006c). Encoded archival description - version 2002 official site. ETD dtd version 2002. Retrieved April 19, 2008 from www.loc.gov/ead/ead2002a.html.

Meissner, D., Kinney, G., Lacy, M., Nelson, N., Proffitt, M., Rinehart, R., Ruddy, D., Stockling, B., Webb, M., \& Young, T. (2002). RLG best practices guidelines for encoded archival description (pp. 1-24). Mountain View: RLG. Retrieved January 5, 2007 from www.rlg.org/en/pdfs/bpg.pdf.

National Library of Australia. (1999). Use of encoded archival description (EAD) for manuscript collection Retrieved January 4, 2007 from www.nla.gov.au/initiatives/ead/eadintro .html.

OCLC. (2007). ArchiveGrid-open the door to history. Retrieved January 4, 2007 from http:/ / archivegrid.org/web.

OCLC. (2008). EAD report card. Retrieved April 11, 2008 www.oclc.org/programs/ourwork/past/ead/reportcard .htm.

Pearce-Moses, R. (2005). A glossary of archival and records terminology. Chicago: Society of American Archivists. Retrieved January 8, 2007 from www.archivists.org/glossary/index.asp.

Prom, C. J. \& Habing, T. G. (2002). Using the open archives initiative protocols with EAD . Paper preserted at the International Conference on Digital Libraries Proceedings of the 2 nd ACM/IEEE-CS Joint Conference on Digital Libraries. Portland, Oregan, USA, July 14-18, 2002. Retrieved October 6, 2006 from http://portal.acm .org/citation.cfm?doid=544220.544255.

Reese, T. (2005). Building lite-weight EAD Repositories,. Paper presented in the International Conference on Digital Libraries Proceedings of the 5th ACM/IEEE-CS Joint Conference on Digital Libraries. New York: ACM. Retrieved January 5, 2007 from http:/ / doi.acm.org/10.1145/1065385.1065498.

Special Collections Department, University of Virginia. (2004). Virginia heritage guides to manuscripts and archival collections in virginia. Retrieved January 7, 2007 from http:/ / ead.lib.virginia .edu/vivaead/.

Thomas, C., et al. (2006). Best practices guidelines for the implementation of EAD version 2002 in Florida institutions. Florida State University Special Collections.

University of Texas Libraries, University of Texas at Austin. (Unknown). Texas Archival Resources Online (TARO). Retrieved January 4, 2007 from www.lib.utexas.edu/taro. 